10 - ORIGINAL ARTICLE

SYSTEMATIC REVIEWS AND META-ANALYSIS

\title{
A meta-analysis of the efficacy of ureteroscopic lithotripsy and extracorporeal shock wave lithotripsy on ureteral calculi
}

\author{
Yahong Xu', Yi Lu' ${ }^{\text {II }}$ Jian Li' ${ }^{I I I}$, Shunwen Luo ${ }^{\text {IV }}$, Yang Liu ${ }^{\text {V }}$ Zhigang Jia ${ }^{\text {VI }}$, Ping Chen ${ }^{\text {VII }}$, Yu Guo ${ }^{\text {VIII }}$, Qihua Zhao ${ }^{\text {IX }}$, Xiaoping Ma ${ }^{\mathrm{X}}$, \\ Shufang Jia ${ }^{\mathrm{XI}}$
}

DOI: http://dx.doi.org/10.1590/S0102-86502014000500010

IPhD, Department of Urology, the $452^{\text {nd }}$ Hospital of People's Liberation Army, Chengdu, China.

Acquisition and interpretation of data, design the protocol, technical procedures, manuscript preparation, supervised all phases of the study.

IIPhD, Department of Urology, the 452 ${ }^{\text {nd }}$ Hospital of People's Liberation Army, Chengdu, China. Supervised all phases of the study.

III $\mathrm{PhD}$, Department of Urology, the 452 ${ }^{\text {nd }}$ Hospital of People's Liberation Army, Chengdu, China. Manuscript writing.

${ }^{\text {IV } M D, ~ D e p a r t m e n t ~ o f ~ U r o l o g y, ~ t h e ~ 452 ~}{ }^{\text {nd }}$ Hospital of People's Liberation Army, Chengdu, China. Acquisition and analysis of data.

${ }^{v} \mathrm{MD}$, Department of Urology, the $452^{\text {nd }}$ Hospital of People's Liberation Army, Chengdu, China. Acquisition and analysis of data.

${ }^{\mathrm{VI}}$ Fellow Master degree, Department of Urology, the $452^{\text {nd }}$ Hospital of People's Liberation Army, Chengdu, China. Acquisition and analysis of data.

VIIPhD, Nursing Department, the 452nd Hospital of People's Liberation Army, Chengdu, China. Acquisition of data.

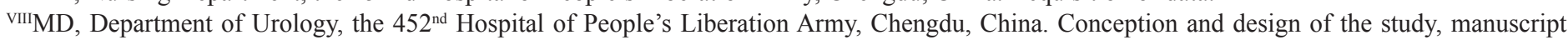
writing, critical revision.

${ }^{\mathrm{IX}} \mathrm{MD}$, Department of Urology, the $452^{\text {nd }}$ Hospital of People's Liberation Army, Chengdu, China. Conception and design of the study, manuscript writing, critical revision.

xPhD, Department of Urology, the 452 $2^{\text {nd }}$ Hospital of People's Liberation Army, Chengdu, China. Acquisition and analysis of data.

${ }^{x} \mathrm{PhD}$, Clinical Laboratory, the 452nd Hospital of People's Liberation Army, Chengdu, China. Conception and design of the study, manuscript writing, critical revision.

\section{ABSTRACT}

PURPOSE: To re-evaluated the clinic efficacy of ureteroscopic lithotripsy (URS) and extracorporeal shock wave lithotripsy (ESWL) on ureteral calculi with Cochrane systematic reviews in this paper.

METHODS: We searched clinical randomized controlled trials and prospective controlled trials in databases such as Cochrane library, Medline, Springer, Elsevier Science Direct, PubMed. Pooled estimate of risk ratios (RRs), standard mean difference (SMD) with 95\% confidence intervals (CIs) were used as measure of effect sizes. Summary effect estimates were also stratified by sample size, study design and study region. The overall effect sizes were derived using a random-effects model or fixed-effects model when appreciated, and meta-analysis were conducted with software RewMan 5.0.

RESULTS: The meta-analysis suggested that there were significant differences of post-treatment stone free rate, repeat treatment rate, patients' satisfaction, incidence of postoperative complications, operation time and hospital stays between ESWL treatment cases and URS treatment cases. But in the sample sizes analysis, there were no significant differences of the post-treatment stone free rate and repeat treatment rate when the sample sizes were less than 100 .

CONCLUSIONS: Compared to the ureteroscopic lithotripsy treatment, extracorporeal shock wave lithotripsy treatment provided a significantly lower post-treatment stone free rate, but it also obviously brought out less postoperative complications, shorter operation time and hospital stays.

Key words: Lithotripsy (MeSH). Ureteroscoy (MeSH). Ureteral Calculi. Meta-Analysis. 


\section{Introduction}

The presence of calculi in the urinary system is defined as urolithiasis, which represents the symptomatic manifestation of various metabolic disturbances, caused by a variety of pathological factors and their interaction ${ }^{1}$. Urolithiasis is a common and frequently-occurring disease with increased morbidity and high recurrence rate, including renal calculi, ureteral calculi, cystolith and urethral calculi, among which ureteral calculi is the most commonly one ${ }^{2}$. So far, ureteroscopic lithotripsy (URS) and extracorporeal shock wave lithotripsy (ESWL) are principle therapies in ureteral calculi treatment with satisfactory curative effect in the vast majority of cases, and both have its own advantages and disadvantages ${ }^{3}$.

ESWL, dates back to 1980 s, is a clinically proved method of totally noninvasive, with low cost, few complications and no or shorter hospitalization ${ }^{4-6}$. URS is more invasive and done under general anaesthesia, but significantly better in terms of operative time, fluoroscopy time and time to achieve a stone-free state ${ }^{6-8}$. URS is also better in broking hard stones and the ureter opening is simultaneously dilated by the scope to facilitate subsequent stone passage. In Middela et al. ${ }^{9}$ study, ESWL was demonstrated an effective and minimally invasive method for treating ureteral stones. While Hong and Park demonstrated that despite the liberal use of ESWL, ureteroscopic lithotripsy was still the preferred treatment modality for managing ureter stones at many hospitals and achieves an immediate stone-free state in a high percent of patients ${ }^{10}$. So it is still controversial which treatment is clinical preferred.

Recently, plenty researches compared URS and ESWL in ureteral calculi therapy, but obtained various results due to the differences in research design, recruit and exclusion criteria, measurement methods and so on. In this paper, we collected clinical prospective studies on URS and ESWL, and applied meta-analysis to evaluate the clinic efficacy of URS and ESWL comprehensively.

\section{Methods}

\section{Source of material}

We retrieved literatures in a systematic way from the Cochrane library, Medline, Springer, Elsevier Science Direct, PubMed and EMbase concerning URS and ESWL treating ureteral calculi with the retrieval deadline of December 2012. The search terms included "ureteral stones", "ureteral calculi", "extracorporeal shock wave lithotripsy" and "ureteroscopy and randomized controlled trials". In addition, a manual search of citations from relevant original studies and review articles was performed for any additional studies.

\section{Inclusion and exclusion criteria}

Studies were included in the meta-analysis if they met the following criteria: (1) research papers publicly published abroad; (2) research objects were adult patients with ureteral diseases definitely diagnosed by imaging; (3) the study design were clinical prospective study; (4) studies should include treatments of ureteroscopic lithotripsy (URS) and extracorporeal shock wave lithotripsy (ESWL); (5) data should be integrity, and the number of cases in different treatment groups as well as cases finished the trials should be explicit; (6) observation index should include authors, published journals and time, patients quantity and their operation time, hospital stays, rate of stone free post treatment, rate of repeat treatment and postoperative complications. Besides, references would be excluded when appeared the following conditions: 1) article was non-English literature; 2) paper was re-publication or the literature was used with same population data; 3) article was non-original literature such as review, letters and comments.

\section{Data extraction and literature evaluation}

The data were independently extracted and collected in unified forms from the primary studies by two reviewers. The data items included study details such as sample size, cases loss to follow-up and/or withdraw and research index/data. Disagreement was defused by discussion or the third researchers.

Jadad scale ${ }^{11}$ was applied to assess the methodological quality of recruited clinical trials based on the extracted information such as study design, patients, and the clinical outcomes. The evaluations were also performed by two assessors independently. The recruited studies were defined with high quality when their Jadad score were $\geq 3$.

\section{Statistical analysis}

Meta-analysis was carried out by RevMan 5.0 provided by the Cochrane Collaboration. The point estimates of RR, SMD and their 95\% CIs were calculated as effect sizes. We assessed the heterogeneity by testing Cochran's Q-statistic ${ }^{12}$ and using $P^{2}=$ $100 \% \times(Q-\mathrm{df}) / Q^{13}$. A significant $Q$-statistic $(P<0.05)$ or $P^{2}$-statistic $\left(I^{2}>50 \%\right)$ indicated heterogeneity were existed between studies, and then the random effect model should be used for meta-analysis. Otherwise, heterogeneity is not significant and the fixed effect model 
was applied. We further conducted subgroup analysis according to sample size $(<100 / \geq 100)$, study design (RCT / Non-randomized) and study region (Europe and America / Asia and Africa) to investigate the impacts of study characteristics on our outcomes.

\section{Results}

\section{Eligible studies and the characteristics}

According to the above retrieval method, 829 potentially relevant trials in total were yielded. After screening their titles, abstracts and full publication reviewing, we removed reviews, case reports and retrospective studies. Finally, a total 13 English papers were eligible and recruited in our analysis ${ }^{14-26}$, whose general characteristics were shown in Table 1. The included studies were published between 1999 and 2013. A total of 2005 patients (998 ESWL treatment cases and 1007 URS treatment cases) were considered in the meta-analysis. The studies' sample size was between 13 and 210. In addition, there were 4 high quality studies with Jadad Score 3 and 9 studies with Jadad Score 2.

TABLE 1 - General characteristics of the 13 eligible literatures trials involved.

\begin{tabular}{|c|c|c|c|c|}
\hline $\begin{array}{l}\text { Study and } \\
\text { Publication } \\
\text { year }\end{array}$ & Country/Region & $\begin{array}{c}\text { sample } \\
\text { size } \\
\text { (ESWL/ } \\
\text { URS) }\end{array}$ & $\begin{array}{l}\text { Follow- } \\
\text { up Time }\end{array}$ & $\begin{array}{l}\text { Jadad } \\
\text { Score }\end{array}$ \\
\hline $\begin{array}{l}\text { Hendrikx, } \\
1999\end{array}$ & The Netherlands & $69 / 87$ & $\begin{array}{c}3 \\
\text { months }\end{array}$ & 3 \\
\hline Peschel, 1999 & Australian & $40 / 40$ & 6 weeks & 2 \\
\hline Pearle, 2001 & The U.S.A & $32 / 32$ & $\begin{array}{c}3 \\
\text { months }\end{array}$ & 3 \\
\hline Zeng, 2002 & China & $210 / 180$ & 4 weeks & 2 \\
\hline Lee, 2006 & Taiwan & $22 / 20$ & NA & 3 \\
\hline Salem, 2009 & Egypt & $100 / 100$ & $\begin{array}{c}3 \\
\text { months }\end{array}$ & 2 \\
\hline Verze, 2010 & Italy & $137 / 136$ & $\begin{array}{c}3 \\
\text { months }\end{array}$ & 2 \\
\hline Lopes, 2012 & Brazil & $13 / 13$ & $\begin{array}{c}2 \\
\text { months }\end{array}$ & 2 \\
\hline Islam, 2012 & Pakistan & $68 / 68$ & $\begin{array}{c}3 \\
\text { months }\end{array}$ & 3 \\
\hline $\begin{array}{l}\text { Hosking, } \\
2003\end{array}$ & Canada & $110 / 172$ & $\begin{array}{c}3 \\
\text { months }\end{array}$ & 2 \\
\hline Honeck, 2006 & Germany & $62 / 62$ & NA & 2 \\
\hline Khalil, 2013 & Kuwait & $37 / 45$ & $\begin{array}{c}3 \\
\text { months }\end{array}$ & 2 \\
\hline $\begin{array}{l}\text { Strohmaier, } \\
1999\end{array}$ & Germany & $97 / 49$ & NA & 2 \\
\hline
\end{tabular}

NA: not available

\section{Meta-analysis of the stone free rate}

All the 13 papers ${ }^{14-26}$ reported the differences of stone free rate of patients after the treatment of ESWL and URS. The heterogeneity results $\left(\mathrm{P}<0.00001, I^{2}=83 \%\right)$ indicated significant heterogeneities were existed between the studies, so we used the random effect model to evaluate the pooled estimates. The pooled RR (95\% CI) was $0.82(0.74-0.90)$ and the p-value of the test for overall effect was less than 0.0001 which demonstrated there was a significant $18 \%$ decrease of stone free rate of patients treated with ESWL compared to the URS surgeries (Figure 1).

\begin{tabular}{|c|c|c|c|c|c|c|c|c|}
\hline \multirow{2}{*}{$\frac{\text { Studv or Subqroup }}{\text { Hendrikx } 1999}$} & \multicolumn{2}{|c|}{$\begin{array}{l}\text { ESWL } \\
\text { Events Total }\end{array}$} & \multicolumn{2}{|c|}{$\begin{array}{l}\text { URS } \\
\text { Events Total }\end{array}$} & \multicolumn{2}{|c|}{$\begin{array}{c}\text { Risk Ratio } \\
\text { Weight } \mathrm{M}-\mathrm{H}, \text { Random, } 95 \% \mathrm{Cl}\end{array}$} & \multicolumn{2}{|c|}{$\begin{array}{c}\text { Risk Ratio } \\
\text { M-H, Random, } 95 \% \mathrm{Cl}\end{array}$} \\
\hline & 35 & 69 & 79 & 87 & $6.5 \%$ & $0.56[0.44,0.71]$ & & \\
\hline Honeck 2006 & 52 & 62 & 61 & 62 & $9.6 \%$ & $0.85[0.76,0.96]$ & $\rightarrow$ & \\
\hline Hosking 2003 & 72 & 110 & 163 & 172 & $9.0 \%$ & $0.69[0.60,0.79]$ & $\rightarrow$ & \\
\hline Islam 2012 & 50 & 68 & 64 & 68 & $8.6 \%$ & $0.78[0.67,0.91]$ & $\rightarrow$ & \\
\hline Khalil 2013 & 29 & 37 & 37 & 45 & $7.0 \%$ & $0.95[0.77,1.18]$ & - & \\
\hline Lee 2006 & 7 & 22 & 7 & 20 & $1.1 \%$ & $0.91[0.39,2.14]$ & & \\
\hline Lopes 2012 & 5 & 14 & 10 & 16 & $1.3 \%$ & $0.57[0.26,1.27]$ & & - \\
\hline Pearle 2001 & 29 & 32 & 29 & 32 & $8.5 \%$ & $1.00[0.85,1.17]$ & & \\
\hline Peschel 1999 & 36 & 40 & 40 & 40 & $9.6 \%$ & $0.90[0.81,1.01]$ & $\rightarrow$ & \\
\hline Salem 2009 & 71 & 100 & 96 & 100 & $9.2 \%$ & $0.74[0.65,0.84]$ & $\rightarrow$ & \\
\hline Strohmaier 1999 & 68 & 97 & 46 & 49 & $8.8 \%$ & $0.75[0.64,0.87]$ & $\rightarrow$ & \\
\hline Verze 2010 & 127 & 137 & 129 & 136 & $10.6 \%$ & $0.98[0.92,1.04]$ & & \\
\hline Zeng 2002 & 164 & 210 & 168 & 180 & $10.3 \%$ & $0.84[0.77,0.91]$ & $\rightarrow$ & \\
\hline Total $(95 \% \mathrm{Cl})$ & & 998 & & 1007 & $100.0 \%$ & $0.82[0.74,0.90]$ & $\bullet$ & \\
\hline Total events & 745 & & 929 & & & & & \\
\hline $\begin{array}{l}\text { Heterogeneity: Tauz } \\
\text { Test for overall effect }\end{array}$ & $\begin{array}{l}0.02 ; \mathrm{Chi}^{2} \\
\mathrm{Z}=4.17\end{array}$ & $\begin{array}{l}=70.2 \\
P<0.00\end{array}$ & $\begin{array}{l}\text { 2, df }=1 \\
001)\end{array}$ & & .00001 & & $\begin{array}{c}0.5 \\
1\end{array}$ & Eavours! \\
\hline
\end{tabular}

FIGURE 1 - Meta-analysis forest plots of stone free rate associated with the ureteroscopic lithotripsy (URS) vs. extracorporeal shock wave lithotripsy (ESWL).

\section{Meta-analysis of the repeat treatment rate}

A total of 10 papers ${ }^{14-21,24,26}$ were analyzed with the repeat treatment rate of patients after the two different therapeutic methods. There was significant heterogeneities $\left(\mathrm{P}<0.00001, I^{2}=85 \%\right)$ between the recruited studies and random effects model was applied for the analysis. The overall estimates of RR was 3.46 (95\% $\mathrm{CI}$ : 1.50-7.97) and the test p-value for overall effect was 0.004 (Figure 2). It pointed out that there were significant differences of repeat treatment rate between the ESWL and URS.

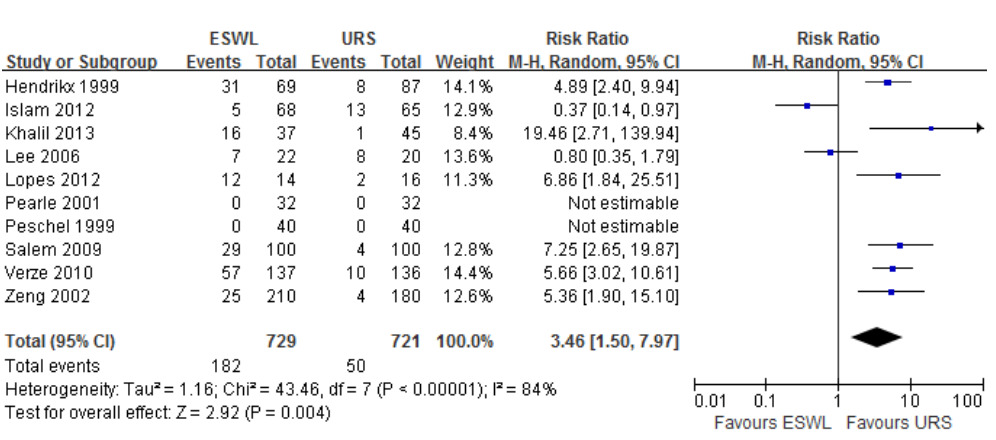

FIGURE 2 - Meta-analysis forest plots of repeat treatment rate associated with the ureteroscopic lithotripsy (URS) vs. extracorporeal shock wave lithotripsy (ESWL). 


\section{Meta-analysis of the patients'satisfaction}

There were only two papers ${ }^{14,17}$ studied the patients' satisfaction after treatment with ESWLand URS. Fixed effects model were chose for the meta-analysis as the no-significant heterogeneity $\left(\mathrm{P}=0.85, \mathrm{I}^{2}=0.0 \%\right)$. In Figure 3 , the total estimates $(\mathrm{P}=0.02$, $\mathrm{RR}=0.87,95 \% \mathrm{CI}: 0.78-0.98)$ showed that patients' satisfaction in URS group was higher than ESWL group significantly.

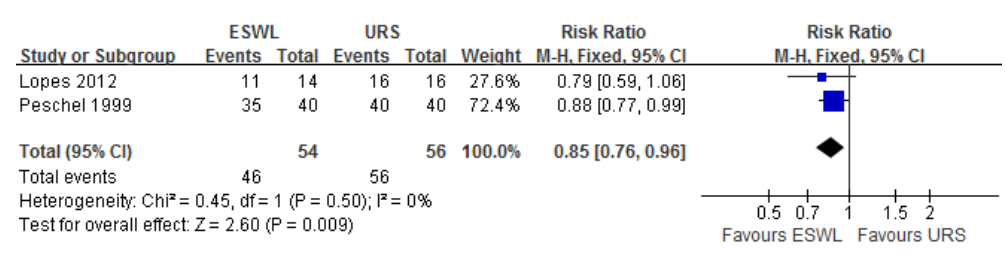

FIGURE 3 - Meta-analysis forest plots of patients' satisfaction in ureteroscopic lithotripsy (URS) treated group and extracorporeal shock wave lithotripsy (ESWL) treated group.

\section{Meta-analysis of the postoperative complications}

A total of 10 papers ${ }^{14-21,24,26}$ were analyzed with patients' postoperative complications. The heterogeneity results $(\mathrm{P}<0.08$, $r^{2}=43 \%$ ) indicated non-significant heterogeneities were existed between the studies, so fixed effects model were applied to evaluate the pooled estimates. The total RR of 0.63 (95\%CI: 0.48 $0.83, \mathrm{P}=0.40$ ) described that $\mathrm{ESWL}$ had a significant $37 \%$ reduce of postoperative complications compared to URS in the ureteral calculi treatment (Figure 4).

\begin{tabular}{|c|c|c|c|c|c|c|c|c|}
\hline \multirow{2}{*}{$\begin{array}{l}\text { Study or Subaroup } \\
\text { Hendrikx } 1999\end{array}$} & \multicolumn{2}{|c|}{$\begin{array}{l}\text { ESWL } \\
\text { Events }\end{array}$} & \multicolumn{2}{|c|}{ URS } & \multicolumn{2}{|c|}{$\begin{array}{cc} & \text { Risk Ratio } \\
\text { Weight } & \text { M-H. Fixed, } 95 \% \mathrm{Cl}\end{array}$} & \multicolumn{2}{|c|}{$\begin{array}{c}\text { Risk Ratio } \\
\text { M-H. Fixed, } 95 \% \mathrm{Cl}\end{array}$} \\
\hline & 14 & 69 & 30 & 87 & $23.8 \%$ & $0.59[0.34,1.02]$ & - & \\
\hline Islam 2012 & 5 & 68 & 6 & 68 & $5.4 \%$ & $0.83[0.27,2.60]$ & & \\
\hline Khalil 2013 & 9 & 37 & 7 & 45 & $5.7 \%$ & $1.56[0.64,3.80]$ & & \\
\hline Lee 2006 & 2 & 22 & 18 & 20 & $16.9 \%$ & $0.10[0.03,0.38]$ & & \\
\hline Lopes 2012 & 1 & 14 & 3 & 16 & $2.5 \%$ & $0.38[0.04,3.26]$ & & \\
\hline Pearle 2001 & 3 & 32 & 8 & 32 & $7.2 \%$ & $0.38[0.11,1.29]$ & & \\
\hline Peschel 1999 & 0 & 40 & 0 & 40 & & Not estimable & & \\
\hline Salem 2009 & 2 & 100 & 4 & 100 & $3.6 \%$ & $0.50[0.09,2.67]$ & & \\
\hline Verze 2010 & 21 & 137 & 26 & 136 & $23.4 \%$ & $0.80[0.47,1.35]$ & - & \\
\hline Zeng 2002 & 12 & 210 & 12 & 180 & $11.6 \%$ & $0.86[0.39,1.86]$ & & \\
\hline Total $(95 \% \mathrm{Cl})$ & & 729 & & 724 & $100.0 \%$ & $0.63[0.48,0.83]$ & 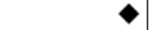 & \\
\hline Total events & 69 & & 114 & & & & & \\
\hline $\begin{array}{l}\text { Heterogeneity: } \mathrm{Chi}^{2}= \\
\text { Test for overall effect }\end{array}$ & $\begin{array}{l}13.97, \mathrm{df}= \\
Z=3.30(\end{array}$ & & $08) ; 1^{2}$ & $=43 \%$ & & & $\begin{array}{l}0.05 \\
\text { Favours ESWL }^{1}\end{array}$ & 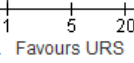 \\
\hline
\end{tabular}

FIGURE 4 - Meta-analysis forest plots of postoperative complications in ureteroscopic lithotripsy (URS) treated group and extracorporeal shock wave lithotripsy (ESWL) treated group.

\section{Meta-analysis of the operation time}

There were three papers ${ }^{17,18,20}$ analyzed the operation time of the two different therapeutic methods. Random effects model were chose due to the poor heterogeneity $\left(\mathrm{P}=0.04, I^{2}=70 \%\right)$. The total estimates $(\mathrm{P}=0.002, \mathrm{SMD}=-1.12,95 \% \mathrm{CI}$ : $-1.81--0.43)$ demonstrated that the operation time in URS group was significant longer than that in the ESWL group (Figure 5).

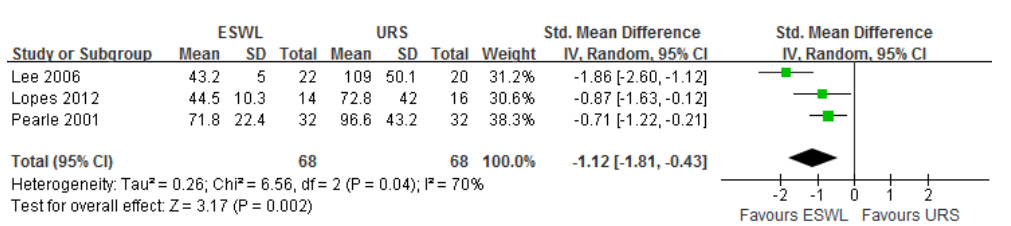

FIGURE 5 - Meta-analysis forest plots of operation time in ureteroscopic lithotripsy (URS) treated group and extracorporeal shock wave lithotripsy (ESWL) treated group.

\section{Meta-analysis of the hospital stays}

There were three papers ${ }^{17,18,20}$ studied the hospital stays of patients with the treatment of ESWL and URS. The heterogeneity results $\left(\mathrm{P}=0.0001, I^{2}=89 \%\right)$ indicated significant heterogeneities were existed between the studies, so random fixed effects model were applied to evaluate the pooled estimates. The pooled estimates $(\mathrm{P}=0.004, \mathrm{SMD}=-1.71,95 \% \mathrm{CI}:-2.88--0.55)$ demonstrated that the hospital stays in URS group was also significant longer than that in the ESWL group (Figure 6).

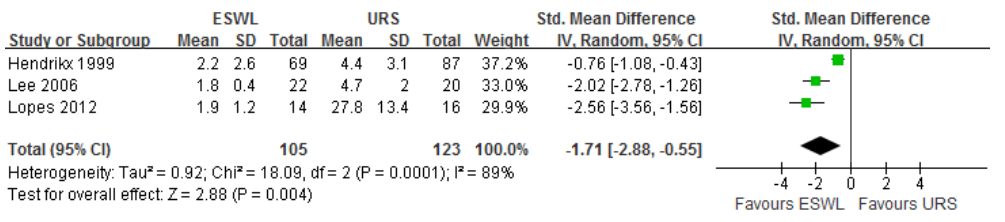

FIGURE 6 - Meta-analysis forest plots of hospital stays in ureteroscopic lithotripsy (URS) treated group and extracorporeal shock wave lithotripsy (ESWL) treated group.

\section{Subgroup analysis}

The subgroup analysis of stone free rate and repeat treatment rate of ureteral calculi patients stratified by the sample size, study design and study region were showed in Tables 2 and 3 , respectively. In the stratified analysis by the sample size, there were no significant difference of the stone free rate $(R R=0.91$; 95\%CI: 0.82-1.02) and repeat treatment rate ( $\mathrm{RR}=4.21 ; 95 \% \mathrm{CI}$ : $0.50-35.60)$ of the patients treated with ESWL and URS when the sample size was smaller than 100. In addition, the outcomes of stone free rate stratified by the study design were $\mathrm{RR}=0.82$ (95\%CI: $0.73-0.93)$ and $\mathrm{RR}=0.80(95 \% \mathrm{CI}: 0.70-0.91)$ of the $\mathrm{RCT}$ and non-randomized studies, respectively, while the repeat treatment rate of $\mathrm{RCT}$ and non-randomized studies were $\mathrm{RR}=2.96$ (95\%CI: 1.25-6.97) and $\mathrm{RR}=19.46$ (2.71-139.94). Besides, the outcomes of subgroups stratified by the study region were $\mathrm{RR}=0.81$ (95\%CI: 0.69-0.94; Europe and America) and $\mathrm{RR}=0.81$ (95\%CI: 0.76-0.88; Asia and Africa) of the stone free rate, and repeat treatment rate were $\mathrm{RR}=5.46$ (95\%CI: 3.51-8.51; Europe and America) and RR=2.64 (95\%CI: 0.66-10.54; Asia and Africa). The results indicated that the outcomes of the stone free rate and 
repeat treatment rate stratified by the study design and study region were consisted with the pooled estimates.

TABLE 2 - Subgroup analyses of stone free rate of ureteral calculi patients treated with ESWL and URS.

\begin{tabular}{|c|c|c|c|c|c|}
\hline \multirow{2}{*}{$\begin{array}{l}\text { Group } \\
\text { All studies }\end{array}$} & \multirow{2}{*}{$\begin{array}{c}\begin{array}{c}\text { No. of } \\
\text { studies }\end{array} \\
13\end{array}$} & \multirow{2}{*}{$\begin{array}{l}\text { RR }(95 \% \mathrm{CI}) \\
0.82 \\
(0.74,0.90)\end{array}$} & \multicolumn{2}{|c|}{ Heterogeneity test } & \multirow{2}{*}{$\begin{array}{c}\text { Significance } \\
\text { test }(P) \\
<0.0001\end{array}$} \\
\hline & & & $<0.00001$ & 83.0 & \\
\hline sample size & & & & & \\
\hline$<100$ & 5 & $\begin{array}{c}0.91 \\
(0.82,1.02)\end{array}$ & 0.60 & 0.0 & 0.11 \\
\hline$\geq 100$ & 8 & $\begin{array}{c}0.78 \\
(0.69,0.88)\end{array}$ & $<0.00001$ & 89.0 & $<0.0001$ \\
\hline study design & & & & & \\
\hline $\mathrm{RCT}$ & 9 & $\begin{array}{c}0.82 \\
(0.73,0.93)\end{array}$ & $<0.00001$ & 85.0 & 0.002 \\
\hline $\begin{array}{l}\text { Non- } \\
\text { randomized } \\
\text { study region }\end{array}$ & 4 & $\begin{array}{c}0.80 \\
(0.70,0.91)\end{array}$ & 0.03 & 68.0 & 0.0007 \\
\hline $\begin{array}{l}\text { Europe and } \\
\text { America }\end{array}$ & 8 & $\begin{array}{c}0.81 \\
(0.69,0.94)\end{array}$ & $<0.00001$ & 90.0 & 0.005 \\
\hline $\begin{array}{l}\text { Asia and } \\
\text { Africa }\end{array}$ & 5 & $\begin{array}{c}0.81 \\
(0.76,0.88) \\
\end{array}$ & 0.30 & 17.0 & $<0.0001$ \\
\hline
\end{tabular}

TABLE 3 - Subgroup analyses of repeat treatment rate of ureteral calculi patients treated with ESWL and URS.

\begin{tabular}{|c|c|c|c|c|c|}
\hline Group & $\begin{array}{l}\text { No. of } \\
\text { studies }\end{array}$ & $\mathrm{RR}(95 \% \mathrm{CI})$ & $\begin{array}{c}\text { Heterogen } \\
P\end{array}$ & $\begin{array}{l}\text { ty test } \\
\%)\end{array}$ & $\begin{array}{l}\text { Significance } \\
\text { test }(P)\end{array}$ \\
\hline $\begin{array}{l}\text { All studies } \\
\text { sample size }\end{array}$ & 10 & $3.46(1.50,7.97)$ & $<0.00001$ & 84.0 & 0.004 \\
\hline$<100$ & 5 & $\begin{array}{c}4.21 \\
(0.50,35.60)\end{array}$ & 0.0003 & 88.0 & 0.19 \\
\hline $\begin{array}{l}\geq 100 \\
\text { study design }\end{array}$ & 5 & $3.36(1.28,8.81)$ & $<0.00001$ & 85.0 & 0.01 \\
\hline $\mathrm{RCT}$ & 9 & $2.96(1.25,6.97)$ & $<0.00001$ & 85.0 & 0.01 \\
\hline $\begin{array}{l}\text { Non- } \\
\text { randomized } \\
\text { study region }\end{array}$ & 1 & $\begin{array}{c}19.46 \\
(2.71,139.94)\end{array}$ & -- & -- & -- \\
\hline $\begin{array}{l}\text { Europe and } \\
\text { America }\end{array}$ & 5 & $5.46(3.51,8.51)$ & 0.89 & 0.0 & $<0.00001$ \\
\hline $\begin{array}{l}\text { Asia and } \\
\text { Africa }\end{array}$ & 5 & $\begin{array}{c}2.64 \\
(0.66,10.54)\end{array}$ & $<0.00001$ & 88.0 & 0.17 \\
\hline
\end{tabular}


differs, which might impact the outcomes. Therefore, further assessment with large sample sizes, clearly subgroup analyses (such as size and position of stones) and uniform follow-up information of postoperative complications should be carried out to evaluate the efficacy of ESWL and URS.

\section{Conclusion}

Extracorporeal shock wave lithotripsy performed with less postoperative complications, shorter operation time and hospital stays, and ureteroscopic lithotripsy provided better efficacy of higher post-treatment stone free rate, lower repeat treatment rate and higher patients' satisfaction on the ureteral calculi treatment.

\section{References}

1. Milliner DS. Urolithiasis, Pediatric nephrology. Springer; 2009. p.1405-30.

2. Xiaoping C, Xidao L. Surgery. People's Publishing House; 2005.

3. Matlaga BR. Contemporary surgical management of upper urinary tract calculi. J Urol. 2009;181(5):2152-6.

4. Powers C, Tinterow M, Burpee J. Extracorporeal shock wave lithotripsy: a study of renal stone differences. Kans Med. 1989;90(1):19-22.

5. Carlsson P, Kinn A-C, Tiselius H-G, Ohlsén H, Rahmqvist M. Cost effectiveness of extracorporeal shock wave lithotripsy and percutaneous nephrolithotomy for medium-sized kidney stones: a randomised clinical trial. Scand J Urol Nephrol. 1992;26(3):257-63.

6. Peschel R, Janetschek G, Bartsch G. Extracorporeal shock wave lithotripsy versus ureteroscopy for distal ureteral calculi: a prospective randomized study. J Urol. 1999;162(6):1909-12.

7. Zanetti G, Seveso M. Extracorporeal shock wave lithotripsy. Arch Ital Urol Androl. 1996;68(4):263-76.

8. Andreoni C, Afane J, Olweny E, Clayman RV. Flexible ureteroscopic lithotripsy: first-line therapy for proximal ureteral and renal calculi in the morbidly obese and superobese patient. J Endourol. 2001;15(5):493-8.

9. Middela S, Papadopoulos G, Srirangam S, Rao P. Extracorporeal shock wave lithotripsy for ureteral stones: do decompression tubes matter? Urology. 2010;76(4):821-5.

10. Hong YK, Park DS. Ureteroscopic lithotripsy using Swiss Lithoclast for treatment of ureteral calculi: 12-years experience. J Korean Med Sci. 2009;24(4):690-4.

11. Jadad AR, Moore RA, Carroll D, Jenkinson C, Reynolds DJ, Gavaghan DJ, McQuay HJ. Assessing the quality of reports of randomized clinical trials: is blinding necessary? Control Clin Trials. 1996;17(1):1-12.

12. Deeks JJ, Altman DG, Bradburn MJ. Statistical methods for examining heterogeneity and combining results from several studies in meta-analysis. Systematic Reviews in Health Care: MetaAnalysis in Context, Second Edition. 2001; p.285-312.

13. Higgins JP, Thompson SG, Deeks JJ, Altman DG. Measuring inconsistency in meta-analyses. BMJ. 2003;327(7414):557-60.

14. Peschel R, Janetschek G, Bartsch G. Extracorporeal shock wave lithotripsy versus ureteroscopy for distal ureteral calculi: a prospective randomized study. J Urol. 1999;162(6):1909-12.
15. Verze P, Imbimbo C, Cancelmo G, Creta M, Palmieri A, Mangiapia F, Buonopane R, Mirone V. Extracorporeal shockwave lithotripsy vs ureteroscopy as first-line therapy for patients with single, distal ureteric stones: a prospective randomized study. BJU Int. 2010;106(11):1748-52.

16. Zeng GQ, Zhong WD, Cai YB, Dai QS, Hu JB, Wei HA Extracorporeal shock-wave versus pneumatic ureteroscopic lithotripsy in treatment of lower ureteral calculi. Asian J Androl. 2002;4(4):303-5.

17. Lopes Neto AC, Korkes F, Silva JL, 2nd, Amarante RD, Mattos MH, Tobias-Machado M, Pompeo AC. Prospective randomized study of treatment of large proximal ureteral stones: extracorporeal shock wave lithotripsy versus ureterolithotripsy versus laparoscopy. J Urol. 2012;187(1):164-8.

18. Lee YH, Tsai JY, Jiaan BP, Wu T, Yu CC. Prospective randomized trial comparing shock wave lithotripsy and ureteroscopic lithotripsy for management of large upper third ureteral stones. Urology. 2006;67(3):480-4.

19. Pearle MS, Nadler R, Bercowsky E, Chen C, Dunn M, Figenshau RS, Hoenig DM, McDougall EM, Mutz J, Nakada SY, Shalhav AL, Sundaram C, Wolf JS, Jr., Clayman RV. Prospective randomized trial comparing shock wave lithotripsy and ureteroscopy for management of distal ureteral calculi. J Urol. 2001;166(4):1255-60.

20. Hendrikx AJ, Strijbos WE, de Knijff DW, Kums JJ, Doesburg WH, Lemmens WA. Treatment for extended-mid and distal ureteral stones: SWL or ureteroscopy? Results of a multicenter study. J Endourol. 1999;13(10):727-33.

21. Islam M, Malik A. Ureteroscopic pneumatic versus extracorporeal shock wave lithotripsy for lower ureteral stones. J Coll Physicians Surg Pak. 2012;22(7):444-7.

22. Honeck P, Häcker A, Alken P, Michel M, Knoll T. Shock wave lithotripsy versus ureteroscopy for distal ureteral calculi: a prospective study. Urol Res. 2006;34(3):190-2.

23. Hosking D, Smith W, McColm S. A comparison of extracorporeal shock wave lithotripsy and ureteroscopy under intravenous sedation for the management of distal ureteric calculi. Can J Urol. 2003;10(2):1780-4.

24. Khalil M. Management of impacted proximal ureteral stone: Extracorporeal shock wave lithotripsy versus ureteroscopy with holmium: YAG laser lithotripsy. Urol Ann. 2013;5(2):88-92.

25. Strohmaier WL, Schubert G, Rosenkranz T, Weigl A. Comparison of extracorporeal shock wave lithotripsy and ureteroscopy in the treatment of ureteral calculi: a prospective study. Eur Urol. 1999;36(5):376-9.

26. Salem HK. A prospective randomized study comparing shock wave lithotripsy and semirigid ureteroscopy for the management of proximal ureteral calculi. Urology. 2009;74(6):1216-21.

27. Aboumarzouk OM, Kata SG, Keeley FX, McClinton S, Nabi G. Extracorporeal shock wave lithotripsy (ESWL) versus ureteroscopic management for ureteric calculi. Cochrane Database Syst Rev. 2012;5: CD006029

28. Chang S, Ho C, Kuo H-C. Ureteroscopic treatment of lower ureteral calculi in the era of extracorporeal shock wave lithotripsy: from a developing country point of view. J Urol. 1993;150(5 Pt 1):1395-8.

29. Hosking DH, Bard RJ. Ureteroscopy with intravenous sedation for treatment of distal ureteral calculi: a safe and effective alternative to shock wave lithotripsy. J Urol. 1996;156(3):899-902.

30. La Rosette D. Treatment of mid-and lower ureteric calculi: extracorporeal shock-wave lithotripsy vs laser ureteroscopy. A comparison of costs, morbidity and effectiveness. Br J Urol. 1998;81(1):31-5.

31. Wills T, Burns J. Ureteroscopy: an outpatient procedure? J Urol. 1994;151(5):1185-7. 
Xu Y et al.

32. Erturk E, Herrman E, Cockett A. Extracorporeal shock wave lithotripsy for distal ureteral stones. J Urol. 1993;149(6):1425-6.

33. Farsi HMA, Mosli HA, Alzimaity M, Bahnassy AA, Ibrahim MA. In situ extracorporeal shock wave lithotripsy for primary ureteric calculi. Urology. 1994;43(6):776-81.

\section{Correspondence:}

Yahong Xu

317 Jiangshun Road, Jiuyanqiao

Jinjiang district, Chengdu 610021, China

Phone: +86-28-86590341

Fax: +86-28-86590341

xuyahong61@hotmail.com

Received: Dec 16, 2013

Review: Feb 19, 2014

Accepted: March 18, 2014

Conflict of interest: none

Financial source: none

Inform where research was performed (division, department and institution) 